\title{
DE LA MIRADA AL TEXTO: LA ENTREVISTA LITERARIA DE ELENA PONIATOWSKA
}

\author{
ALICIA RUEDA-ACEDO \\ University of Texas, Arlington \\ UC-Mexicanistas
}

En este ensayo se explora la entrevista de Elena Poniatowska como género literario y se ofrece una visión panorámica de la cuestión que permita proponer las bases para su poética ${ }^{1}$. Diversos autores se han dedicado al estudio de la entrevista como género literario; entre ellos destacan Sebastiá Bernal, Albert Chillón, Leonor Alfurch, David Vidal y Montserrat Quesada², quien acuñó el término de entrevista de creación o literaria para referirse a este tipo de textos en consonancia con la clasificación propuesta por Bernal y Chillón de géneros informativos de creación. Éstos se caracterizan por permitir «la subjetividad del informador, la ruptura de la compartimentación tradicional en géneros periodísticos estancos, el uso de múltiples técnicas narrativas y la renuncia a las estructuras rígidas y estereotipadas propias del periodismo convencional» (López Hidalgo, p. 32). Así, tales piezas literarias no están suscritas a una fecha y contexto fijos, sino que tienen una singularidad que hace que pervivan y trasciendan en la historia.

En este tipo de entrevista, el encuentro real entre periodista y entrevistado podría considerarse como un género discursivo primario que se integra, reelaborado, en la entrevista escrita entendida como un género discursivo secundario, a la luz del pensamiento de Mijail Bajtín ${ }^{3}$ Sobre este punto, es interesante señalar la distinción de los actantes que participan en el diálogo mantenido entre el periodista y la persona entrevistada, en

un lugar determinado y hora concreta, y la distinción de entrevistador y personaje en el texto resultante. Dadas e integradas estas características podemos considerar la entrevista como género no estrictamente oral sino $p a-$ raoral ${ }^{4}$. En la entrevista, al igual que en otros géneros literarios, existe un lenguaje literario $\mathrm{y}$ atemporal en el que se pueden distinguir elementos como la voz narrativa, la distinción entre autor/narrador/ personaje, el tiempo, su velocidad y frecuencia, así como los modos del relato, entre otras características. Estos elementos contribuyen a que las entrevistas se conviertan en piezas narrativas en las que la relación entre entrevistador, entrevistado, lugar y tiempo de realización de la entrevista, dé lugar a un proceso de ficcionalización o teatralización. Asimismo, tal y como apunta Roland Barthes ${ }^{5}$, en la entrevista surge un proceso de subordinación y jerarquización de lo expuesto por el entrevistado cuando se realiza la fase conocida como «escripción», y

1

Pese a ser uno de los géneros más cultivados por Elena Poniatowska desde que en 1953 iniciara su labor periodística en el diario mexicano El Excelsior, sus entrevistas no han llamado la atención de la crítica con la profundidad que amerita. Un total de 68 entrevistas han sido compiladas en Palabras cruzadas (1961), Domingo 7 (1982) y Todo México (volúmenes del I al VIII; 1990-2003). La gama de personajes entrevistados oscila entre escritores, actores, políticos, periodistas, cantantes, fotógrafos y otros personajes de interés en su mayoría mexicanos, con residencia o de visita en México, aunque también se encuentran numerosos personajes del ámbito internacional.
Alicia Rueda-Acedo

Profesora de la Universidad de Texas, realizó sus estudios en España (Sevilla y Granada), entre sus numerosas investigaciones destaca su «Homenaje a Elena Poniatowska: acercamientos a la vida y la obra de la escritora mexicana», así como «Visiones trasatlánticas: la entrevista y el reportaje en Elena Poniatowska y Rosa Montero», sin olvidar otros autores como Héctor Aguilar Camín numerosas reseñas como la de Las siete cabritas.

2

Pueden añadirse a esta lista el estudio de Miriam Rodríguez Betancourt, entre otros.

3

Véase «El problema de los géneros discursivos», ensayo integrante de Estética de la creación verbal (1982) en donde Bajtín distingue entre géneros discursivos primarios y secundarios «-a saber, novelas, dramas, investigaciones científicas de toda clase, grandes géneros periodísticos, etc.- [que] surgen en condiciones de la comunicación cultural más compleja, relativamente más desarrollada y organizada, principalmente escrita» (p. 250). Según Bajtín, en su formación, los géneros primarios "constituidos en la comunicación discursiva inmediata» son absorbidos y reelaborados por los géneros secundarios (id.).

4

Término designado por David Vidal, para quien «la entrevista periodística escrita deviene un género con todas las condiciones propias de la escritura, pero que se caracteriza por su estilo -sintaxis, gramática y opciones léxicas- marcadamente oral y por el hecho que tiene como característica genérica ofrecer un suplemento de presencia del personaje [...] crear en el lector la sensación de que ha sido restituida una conversación a veces íntima con el personaje [...] Cuando iniciemos el proceso de escriturización de una entrevista hemos de ser conscientes de esta característica de paraoralidad del género, situado en algún punto intermedio del eje oralidad-escritura, ya que es uno de los grandes atractivos del género y -lo que es más importanteuna de sus principales constantes genéricas» (p. 354).

Véase su ensayo «Del habla a la escritura».

De la mirada al texto: la entrevista literaria de Elena Poniatowska 
Este aspecto lo han señalado críticos como Jorge Halperín, David Vidal y Montserrat Quesada. Véase la bibliografía al final de este trabajo.

7

Ricardo Senabre en "Sobre el estatuto genérico de la biografía» define el término forma biográfica como "un molde en el que pueden verterse contenidos diversos» (p. 34), para luego matizar que "cuando la biografía rebasa los estrechos límites de la historia, ya es otra cosa, aunque esa cosa tenga forma autobiográfica» (p. 35)

8

Este mismo tipo de entrevistarelato, en el que se nos presenta una introducción, nudo y desenlace, se aprecia en las entrevistas hechas a Irma Serrano, María Félix y Marlene Dietrich, por citar algunos ejemplos.

9

Se entiende por ladillos «los titulillos que se colocan dentro de una columna de texto, bien justificados a un lado $-y$ de ahí el nombre- o al centro» (Libro de Estilo de El País, p. 57). También se les denomina intertítulos y su "función es desahogar la densidad del texto» (Echeverría, p. 53).

De la mirada al texto: la entrevista literaria de Elena Poniatowska ALICIA RUEDA-ACEDO que otros autores señalan como traducción/ reconstrucción/transcripción del diálogo. Las ideas expuestas por el entrevistado están sometidas a una doble jerarquización: por un lado la «escripción» y por otro el orden que a estas ideas se les da en el texto. De todo ello se observa que periodista y entrevistado tienen un rol asimétrico que requiere de una responsabilidad ética por parte del periodista, quien debe evitar el protagonismo dentro de la entrevista ${ }^{6}$. Además, la entrevista literaria adopta mecanismos de la ficción, ya que pareciera que la figura del autor (periodista de carne y hueso) y la del entrevistador (voz narrativa integrante del texto) es la misma, pero no es así: al incluirse el autor como entrevistador en el texto de la entrevista como una de las voces del trabado polifónico que en ella se presenta, se autoconfiere cualidad de personaje junto al entrevistado.

Otro de los aspectos destacables de la entrevista de creación es el componente biográfico hasta el punto de poder considerarlas formas biográficas?. Leonor Arfuch ha destacado que «la entrevista íntima suele rondar el terreno de la biografía o la autobiografía» (1995, p. 133). A este respecto, nos podemos servir de las categorías de "pacto autobiográfico» y «pacto de lectura» trabajadas por Lejeune: si bien el entrevistado no firma su «autobiografía», existe un pacto de lectura entre el periodista y el lector y el medio en que se publica la entrevista; el periodista asume la veracidad de lo expuesto como si del propio entrevistado se tratara (p. 44). También podríamos destacar la existencia de un pacto tácito entre el periodista y el entrevistado, ya que se asume que lo que el primero redacta en la entrevista es fiel a lo que el segundo dijo durante el encuentro mantenido entre ambos. Esta «veracidad» de lo contenido en la entrevista oral se construye y valida a la hora de redactar el texto a través de medios narrativos de ficción, rasgo que también ha sido apuntado por Lejeune como característica verosímil de la autobiografía.

Entre estos medios narrativos propios de la ficción se encuentra la teatralización, una de las características integrantes de la poética de la entrevista de Elena Poniatowska. Así, se observa cómo la autora da forma narrativa y/o teatral a muchas de sus entrevistas dotándolas de un comienzo, desarrollo y desenlace, tal como si de un cuento o pieza teatral se tratara ${ }^{8}$. Ejemplo de este tipo de entrevista es «El Santo a dos que tres caídas. El santoral de Rodolfo Guzmán, el Santo» (Todo México vol. I) en la que observamos un comienzo: llegada del luchador a la casa de Poniatowska creando gran expectación entre las vecinas, un desarrollo de la conversación y la asistencia de la entrevistadora a un combate con sus hijos. Llama la atención de manera especial la entradilla de esta entrevista en absoluto convencional, ya que no hace referencia a los datos personales o biográficos del entrevistado ni al lugar donde se desarrolla el encuentro. Por el contrario, Poniatowska nos lleva a su mundo cotidiano en el que, de repente, irrumpe el superhéroe causando un gran revuelo entre Chabelita, empleada del hogar de la entrevistadora, y otras mujeres del barrio:

- ¡Señora, señora, ya llegó y viene enmascarado!» $[\ldots]$

Lástima que los niños estén en la escuela. En la biblioteca, de pie en medio de la alfombra, un hombre de porte atlético [...] una máscara de tela de plata ajustada por medio de un cierre en la parte trasera, no permite ver ni el color de sus ojos. Su mano es fuerte; en realidad se trata de un hombre fornido. Es el Santo. No he sacado la grabadora cuando baja Chabelita:

-Señora, ¿qué los señores no van a querer café? (p. 255).

Se observa cómo de manera sorprendente y nada convencional al género entrevista, Poniatowska inicia su relato con una entradilla en la que aparecen distintos personajes que mantienen un diálogo y representan una escena: la llegada del superhéroe a casa de la periodista. Acto seguido, Poniatowska introduce un ladillo9 («Todas las muchachas de la cuadra») que condensa y enfatiza lo que a continuación sucede:

Cinco minutos después, con una eficacia inaudita -no he iniciado aún la entrevista- entra Chabelita con la azucarera; Josefina con una cuchara; Petra con otra; Tere con una servilleta de papel; Meche con otra; Tomasita con una jarrita de leche; Magda con una charola; Berta, cafetera en mano, se tropieza con Luz; Cata trae un mantel, jun mantel, háganme el favor! [...] y todas se arremolinan en torno al Santo para servirle su cafecito [...] El timbre de la puerta repiquetea, un ejército de mujeres que se secan las manos en el delantal entra $[. .$.$] ; Ya quisiera$ un político tener el pegue del Santo! (pp. 255-56).

A este ejército se suman pepenadores, el afilador de cuchillos, el cartero, cinco monjas de la residencia de San Vicente de Paul, el dueño de la miscelánea... un revuelo de 
personajes que logran que, tal y como señala la entrevistadora, en cinco minutos cambie su vida y le pregunte con admiración: $«-\dot{L}$ Le satisface el cariño que le demuestra la gente?» (pp. 256-57). Comienza, tras esta larga introducción, la entrevista propiamente dicha que se articula a partir de este momento en torno al binomio pregunta-respuesta hasta llegar a la parte en la que Poniatowska y sus hijos Felipe y Paula acuden al combate del Santo. Este hecho, que ocupa una parte muy significativa, puede considerarse como una crónica periodística dentro de la entrevista, ya que Poniatowska nos relata en primera persona el combate, el ambiente que lo rodea y las emociones vividas durante el mismo. Otra de las reglas que rompe la inserción de esta crónica es el protagonismo que no sólo cobra la entrevistadora al convertirse en protagonista, sino el hecho de que nos lleve al terreno de su vida privada, pues los personajes principales de la crónica no son sólo el Santo y los demás luchadores, sino los propios hijos de Poniatowska que se convierten en piezas clave entre los asistentes al combate:

Esto se va a poner feo. Y yo aquí sola con los niños [...] Felipe y Paula escuchan, comen cacahuates, piden refrescos, chupan pastillas y preguntan incasablemente: ¿ «Y tú, ¿cómo te llamas?» [...] a tal grado, que al final nos despedimos de abrazo [...] se oye un rugido, un graznido como de sapos: « Sangre! ¡Sangre!» Entonces Felipe, sin que yo lo pueda detener, corre al ring, se acerca y grita ya con sus últimas fuerzas: «¡Paren esto! ¡Paren, lo van a matar!». Voy por él [...] «iSangre! ¡Sangre! ¡Sangre! ¡Sácale el mole!» Entonces Paula, de seis años, voltea y aúlla ante mi gran asombro: «iQue se la saque a tu abuela!» Estoy descubriendo el carácter de mis hijos (pp. 271-73).

El ejemplo anterior basta para ver cómo Poniatowska se aleja por completo del periodismo convencional asido al estrecho corsé de la pretendida «objetividad». Si ella se convierte en personaje coprotagonista, sus propios hijos y Chabelita pasan a ser personajes secundarios de la entrevista, y los asistentes al combate se convierten en un personaje colectivo del mismo modo que los habitantes del barrio que revolotean en torno al Santo al inicio del relato. Poniatowska nos describe cómo al llegar al Toreo de Cuatro Caminos, lugar del combate, junto a ellos entran «enchamarrados, encamisados, pelos largos, envaselinados y muchas mujeres rechonchitas y de pelo pintado» que junto a policías «que hacen como que la virgen les habla» alternan con los bebedores de ron con coca y con las mujeres que «empinan sus vasos de plástico, muy desinhibidas las gorditas». En palabras de la periodista: «Es el reino del poliéster y del dacrón» (p. 271). Poniatowska logra describir mediante su crónica y una profusa adjetivación a esta muchedumbre de "gritos ensordecedores medio cavernarios» de «bocazas que se abren, ya sea para engullir cervezas - una tras otra-, o aullar como Tarzán de la selva: «¡Sangre! ¡Sangre!» (p. 274). Alcanza así la entrevistadora, mediante la descripción y el desarrollo escenográfico y gracias a su mirada semiótica $^{10}$, trasladar al lector a la esencia del cuadrilátero y sus pobladas gradas, proveyendo de significado el entorno al que pertenece el luchador y ayudándonos a conocerlo y entenderlo mejor.

Las descripciones físicas y el vestuario de los personajes que Poniatowska realiza junto a la puesta en escena también contribuyen a la teatralización. El caso del Santo es, sin lugar a dudas, altamente significativo no sólo por la máscara que siempre cubre su rostro en público y con la que se apersona en la entrevista, sino también por los detalles prosopográficos que Poniatowska destaca del luchador y que pasan de lo meramente físico a lo espiritual:

En el ring, Santo se quita la capa de plata y de terciopelo rojo y tengo conciencia de que ya no es un luchador joven [...] la espalda se le ha aflojado a la altura de la cintura y es allí donde se notan los años. Sin embargo, su constancia, su valentía, su figura legendaria, se han ganado el respeto, el cariño de todos. Su aureola es muy grande (p. 276).

Esta capacidad de Elena Poniatowska de radiografiar al personaje en su entorno que trasciende de lo netamente físico o espacial y alcanza la esencia del personaje se ve claramente en la descripción que la reportera hace de la casa de la actriz Irma Serrano (Todo México vol. II) en la que, aterrada, se pregunta: «¿Cómo describir la casa de Irma Serrano? Así como su dueña está más allá del bien y del mal, 'La Guarida de la Tigresa' está más allá de lo bello y lo feo, más allá de cualquier clasificación» (p. 107). Como si de una cámara se tratara, el ojo de Poniatowska recorre el «cuarto repleto de drapeados, cortinajes, pieles de tigre, cebra, leopardo» (id.) y en otro movimiento de cámara nos lleva hasta la tina «como la de Cleopatra en las películas de Cecil B. de Mille» (p. 108), en donde nos acerca mediante un plano detalle o close up a «un pelo largo, más largo y más triste que la
10

David Vidal denomina mirada semiótica a aquella que "otorga un sentido, un significado simbólico a los objetos que aparecen, por voluntad o no del entrevistado, en la escena del encuentro» (p. 350).

De la mirada al texto: la entrevista literaria de Elena Poniatowska ALICIA RUEDA-ACEDO 


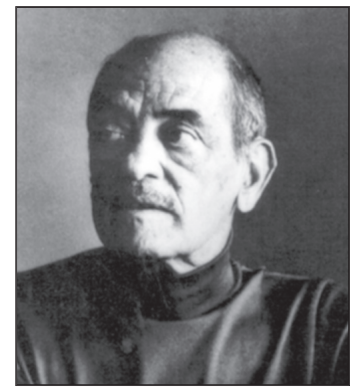

Luis Buñuel.

11

Otras entrevistas en las que se aprecia claramente la fusión del personaje con su entorno son las que Poniatowska realiza a Pita Amor, María Félix, María Conesa y a Tongolele.

12

Rosario Castellanos afirma en "La entrevista: un arte difícil», ensayo incluido en El mar y sus pescaditos» (1975), que este género posee un "ángulo que muestra el talento del entrevistador, la auténtica dignidad del entrevistado y la importancia de la entrevista como género literario» (p. 106).

De la mirada al texto: la entrevista literaria de Elena Poniatowska ALICIA RUEDA-ACEDO cuaresma» (id.). La escena causa tal horror en Poniatowska $-\mathrm{y}$ en sus lectores- que no se atreve - dice- a «ver nada con detenimiento, porque todo me parece apabullante, pero apabullante de feo, y no, no puedo verlo con sentido crítico porque me deja anonadada» (id.). El grosero detalle del pelo, la bañera de Cleopatra, las pieles y drapeados, el olor a circo que dice percibir, complementan la descripción prosopográfica de la actriz de ojos «delineados con rayotas aerodinámicas, espaciales, como de fórmula uno» y de boca «pintada con brocha gorda» (p. 85). Mediante la descripción de la apariencia de Irma Serrano, del entorno que habita y del lenguaje soez y vulgar empleado durante la entrevista, Poniatowska consigue representar una descripción integral que permite al lector casi «tocar el alma» (el cuerpo, más bien) del personaje ${ }^{11}$.

El «talento del entrevistador», como característica de la entrevista literaria según Rosario Castellanos ${ }^{12}$, se aprecia notablemente en el acercamiento y representación que Poniatowska realiza de sus personajes. Ya observamos cómo la escritora se aleja por completo del código deontológico del periodismo informativo que promulga que el periodista no debe compartir protagonismo con el personaje entrevistado. El siguiente aldabonazo consiste en expresar abiertamente sus opiniones e impresiones acerca de los entrevistados y cuán bien o mal le caen. Se pueden distinguir diversas maneras en las que Poniatowska se presenta ante sus personajes dependiendo de la impresión que le causen, si bien en una misma entrevista observamos cómo puede oscilar de un tono confidente $\mathrm{y}$ amable a otro retador e inquisitivo pero siempre en diálogo con la persona que tiene por delante.

Percibimos un ejemplo de este acercamiento desafiante de Poniatowska a su entrevistado en entrevistas como ésta concedida por Irma Serrano en la que, tras la entradilla, Poniatowska dispara a quemarropa: «-Yo creí que usted era un yegua muy arisca, un caballote muy grande... ¿Y su agresividad?» (p. 86) para luego seguir asediándola con otras preguntas del tipo: "¿Por qué va usted a la Procuraduría vestida de pirata?» (p. 98) o "¿a qué huele todo? Huele a zoológico, huele rarísimo» (p. 109). Como es de esperar, las respuestas de «La Tigresa» no sólo están acorde con el tono de las preguntas sino que lo superan: «Mire, yo a las que critican mi casa las mando al carajo» (id.).
En esta sintonía se encuentra la entrevista que Poniatowska realizara al actor Mario Moreno, «Cantinflas», recogida en el mismo tomo. Después de llamar al actor «Don Cantinflitas» se suceden una serie de preguntas que colman la paciencia del actor y lo irritan: «¿Es cierto que a usted no le gusta la gente morena?» (p. 176) o «¿Y le gustó cómo salió el mural de mosaiquitos de colores que le hizo Diego o lo dibujó a usted con cara de sapo como él?» (p. 177).

Otra de las formas de abordar al personaje utilizada recurrentemente por Poniatowska corresponde a lo que podríamos denominar como «acercamiento coral», mediante el cual la periodista nos ofrece un collage en el que combina su propia voz con voces y textos de muy diversa índole que rodean al personaje. Ejemplo claro de este tipo de entrevista es la realizada a su tía "Guadalupe Amor» (Todo México vol. V) en la que distinguimos cuatro voces: la de la entrevistadora y la entrevista$\mathrm{da}$, la de los hermanos de esta última y la de su propia obra poética. En esta entrevista se combinan a la perfección poemas y epitafios de la entrevistada, recuerdos de sus hermanos junto a los de la propia entrevistadora, diálogos recreados de la infancia de la poeta y un breve diálogo entre sobrina y tía; toda esta situación teje un entramado polifónico en el que se hace eco de la voz y visión de Poniatowska sobre Pita. Este mismo procedimiento se observa en otras entrevistas como la concedida por el Santo, que aquí hemos visto. Mediante la presentación del efecto que causa el luchador entre los habitantes del barrio y los asistentes al combate obtenemos una aproximación polifónica al personaje.

De similares características es la entrevista concedida por Luis Buñuel (Todo México vol. I), en la que Poniatowska intercala sus preguntas con las respuestas del director de cine, las intervenciones de su esposa Jeanne Rucar, poemas de Machado y dichos populares, así como con fragmentos de la autobiografía que escribiera Buñuel junto a Jean-Claude Carrière, Mi último suspiro (1982). Todos estos elementos engarzados por Poniatowska permiten que desde muy distintas perspectivas tengamos un acercamiento global al personaje.

Gracias al arte de la conversación y a la curiosidad indagadora de Poniatowska en sus entrevistas se aprecia también un tono íntimo que en ocasiones propicia lo que desde el punto de vista periodístico podría ser considerado un hallazgo, una exclusiva, como sucede 
cuando Lola Álvarez Bravo (Todo México vol. II) confiesa amar todavía a Manuel Álvarez Bravo en su "panteón particular» (p. 47) o cuando con la frase «hasta hoy te lo cuento, Gabriel García Márquez (Todo México vol. I) admite no haber aceptado el premio de la Bienal de São Paulo porque no "recibiría dinero de un gobierno represivo y torturador como era el de Brasil» (p. 217).

Una característica fundamental y definitoria de la poética de la entrevista de Elena Poniatowska es el uso sólido y certero que hace de la documentación previa al encuentro con las personas elegidas para la entrevista. La información recabada por la periodista es crucial a la hora de afrontar y enfrentar al personaje, y marca la diferencia asimétrica que los roles de entrevistador y entrevistado tienen durante el encuentro. Sólo en algunas de sus primeras entrevistas, en la década de los cincuenta, se advierte la falta de documentación previa, como cuando entrevista a la fadista Amalia Rodrigues (Todo México vol. VI) - «le pregunté tonterías» (p. 174), «ni siquiera sé que es un fado» (p. 175) -; al actor Mario Moreno (Todo México vol. IV) - «Pues quiero saber dónde nació usted» (p.176); y al escritor François Mauriac (Todo México vol. IV): «-¿Ha leído usted algunas obras mías? -No, señor Mauriac. Apenas voy a comenzar [...] -De nada serviría que le conteste, señorita, usted no conoce mi pensamiento» (p. 37).

Esta falta de preparación, a veces rayana en la ingenuidad, desaparece a medida que avanza la carrera de Elena Poniatowska como entrevistadora, y la candidez que se advierte en entrevistas posteriores es -en mi opinión- resultado de una estrategia para enervar, provocar o sonsacar al entrevistado, como se aprecia en la pregunta sobre el olor a zoológico en la recámara de Irma Serrano o como cuando le pregunta a Gabriel García Márquez, sin aparente maldad, si guarda copia de sus obras en el Banco de Londres, a lo que el escritor colombiano responde: $-¿$ Ves? ¿Lo ves? ¡Eres mala! No tienes remedio ¡eres mala!» (p. 198).

Es, pues, una nota común en las entrevistas de Poniatowska el hecho de que acuda al encuentro con sus personajes pertrechada de la información suficiente para mantener una conversación vivaz, honda e inteligente. Muestra de esta preocupación de Poniatowska por la información documentada es que cada entrevista de los tomos de Todo México contiene un apéndice al que podríamos llamar biográfico-profesional ${ }^{13}$. Allí la autora resume la información más relevante de la entrevista y destaca los aspectos más importantes de la biografía de los entrevistados, así como los datos más significativos de su carrera profesional. El lector, al concluir la lectura de la entrevista y del apéndice tiene la certeza de que se han cubierto los aspectos esenciales de la persona entrevistada.

En lo que a la estructura formal de la entrevista poniatowskiana respecta, además de contener el apéndice mencionado, cada una presenta ladillos que diagraman el texto condensando y enfatizando las declaraciones más importantes de los entrevistados o bien responden a un ejercicio de composición estilística que juega con lo dicho por el personaje. En lo que respecta al inicio, desarrollo y conclusión de la entrevista, se observa que casi todas incluyen en su totalidad o en gran parte el modelo pregunta-respuesta que viene bien proporcionado desde el principio, o corresponde al cuerpo de la entrevista. Asimismo, en gran parte de ellas Poniatowska incluye una entradilla y un párrafo de salida que en ocasiones distan del concepto tradicional, puesto que no suelen incluir datos de los entrevistados sino que más bien hacen referencia a las impresiones que éstos causan en la escritora. Otra de las características recurrentes es la inclusión de párrafos ilativos-descriptivos ${ }^{14}$ en los que la entrevistadora hace referencia al lugar de la entrevista, comportamiento, detalles físicos o biográficos del personaje o al transcurso de la entrevista-recuérdese, por ejemplo, la descripción de la recámara de Irma Serrano.

Además de estos aspectos formales, las entrevistas de Poniatowska presentan en común la inclusión de imágenes que sirven como apoyo o soporte gráfico, y representan una función fundamental en la concepción global del personaje entrevistado. Así, la primera fotografía de «Guadalupe Amor» que acompaña al primer poema muestra a una Pita entristecida, ausente, que parece transmitir la misma sensación descrita por la poeta «cuyo corazón salió herido» y su «conciencia turbada» (p. 259). Poema e imagen hacen eco en la entrevista a las palabras de Poniatowska, quien retrata la belleza, la provocación y la angustia de la entrevistada.

Otro ejemplo en el que se funden fotografías e imágenes con las palabras de Poniatowska es en la entrevista de Irma Serrano. Si la periodista menciona los ojos con «rayotas aerodinámicas, espaciales, como de fórmula uno» y la boca pintada con «brocha gorda»

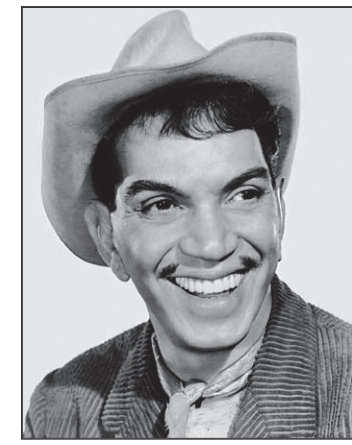

Mario Moreno «Cantinflas».

13

Esta información incluye en numerosas ocasiones una bibliografía. Además en varios de los tomos Poniatowska agradece a distintos colaboradores tanto la recopilación de las entrevistas como la obtención de datos biográficos.

14

David Vidal denomina "excursus» a este tipo de párrafos.
De la mirada al texto: la entrevista literaria de Elena Poniatowska ALICIA RUEDA-ACEDO 


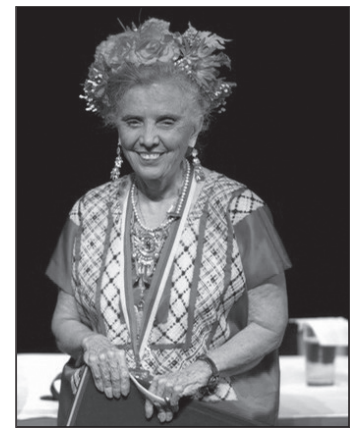

15

Rosario Castellanos afirma que este género posee un "ángulo que muestra el talento del entrevistador, la auténtica dignidad del entrevistado y la importancia de la entrevista como género literario» (op. cit., p. 106).

16

No puede pasar desapercibido que la crónica del México de los años veinte y treinta que Poniatowska presenta en la entrevista a Lola Álvarez Bravo es semilla de libros futuros como Las siete cabritas (2000), en el que dos de sus integrantes María Izquierdo y Pita Amor fueron entrevistados por Poniatowska. Otros personajes entrevistados por la autora como Benita $\mathrm{Ga}^{-}$ leana son cruciales para entender un libro como Tinísima (1992). Del mismo modo, no puede pasar desapercibido que Hasta no verte Jesús mío (1969) es en el origen y en el fondo una entrevista literaria.

De la mirada al texto: la entrevista literaria de Elena Poniatowska ALICIA RUEDA-ACEDO (p. 85), la fotografía precedente a este párrafo es un plano detalle del rostro de la Tigresa en actitud agresiva, en la que se aprecian claramente los rasgos descritos y el «tradicional lunarsote $[s i c]$ tan grande que parece los que la corte de Luis XIV recortaba en terciopelo negro» (p. 86).

En líneas generales, el fotoperiodismo tiene un papel muy importante en cada uno de los volúmenes de Todo México ya que, además de las fotografías y caricaturas que de los personajes se incluyen en cada entrevista, a la mitad de cada tomo se incluyen retratos de mayor tamaño en solitario o fotografías de los mismos protagonistas en compañía de familiares u otros personajes públicos. También aparecen fotogramas de sus películas, imágenes de sus actuaciones o reproducciones de sus obras. Todo este material de gran valor estético e informativo es integrado armónicamente en el texto amplificando y complementando la visión que del personaje presenta Poniatowska.

En cuanto al lenguaje empleado en sus entrevistas, se han de señalar como rasgos principales la adjetivación copiosa, el uso prolífico de metáforas y el reflejo de la oralidad del encuentro. Como ejemplo de las dos primeras características sirva la entradilla que abre la entrevista concedida por Dolores del Río (Todo México vol. II):

¡Sonrió! Entró rápidamente al escenario con su capa flotante y nos sonrió. Una sonrisa blanca, sana, joven; una sonrisa en la que relampaguea toda su vida; hay luz en sus dientes, y una sonrisa de agua limpia, de mar, con velas y sal y yodo y barcos que aguardan. ¡Dios mío! Qué hermosa mujer y qué hermoso su apego a la vida, su diario heroísmo de proyectos, inquietudes, sueños nuevos. Dolores del Río no mira hacia atrás, no corre el peligro de convertirse en estatua de sal (p. 7).

En lo que a la reproducción de la oralidad del encuentro se refiere, a veces Poniatowska hace uso de un lenguaje muy coloquial en el que abundan las interjecciones y exclamaciones y expresiones del tipo: «¿a poco?», «oiga», «ay», etc., y si el personaje pronuncia de manera que llama la atención de la reportera ésta no duda en transcribir, por ejemplo, el acento andaluz del torero Manuel Benítez, el Cordobés (Todo México vol. I) o cómo el Santo pronuncia «rin» por ring, «pasié» por paseé o «machamaca» por matchmaker.

Revisadas estas características generales, podemos sentar las bases para definir la poé- tica de las entrevistas de Elena Poniatowska: el trabajo de documentación como as en la manga a la hora de asistir al encuentro con el personaje y que es empleado para formular preguntas, elaborar los párrafos ilativo-descriptivos y para cuestionar y rebatir al entrevistado; una manera personalísima de abordar al entrevistado que conjuga lo retador con lo confidente pero que siempre convida a un diálogo que puede ser coral, invitando a otras voces y textos que hacen eco de la propia voz de Poniatowska en sus entrevistas de carácter polifónico. En cuanto a la diagramación de sus textos, destaca la estructuración de la entrevista mediante ladillos que resaltan las declaraciones de las personas entrevistadas y la presencia en numerosas ocasiones de entradillas y párrafos de salida de alto contenido literario. Junto a ellos figura la presencia de un soporte gráfico en gran armonía con la entrevista que refuerza y multiplica lo expuesto por la autora sobre el personaje.

Todo lo anterior se acompaña de abundancia de adjetivos y personificaciones y de un lenguaje, acción y ritmo literarios que nos permiten constatar, como diría Rosario Castellanos, «el talento del entrevistador» en el arte de escuchar y representar al sujeto de la escritura y «la dignidad del personaje entrevistado» ${ }^{15}$ entendida ésta como la descripción y representación integral y esencial del personaje cuya vida es presentada en forma biográfica e histórica puesto que estas entrevistas se convierten en obras atemporales.

Por último, la entrevista poniatowskiana es uno de los ejes motores de toda la obra literaria de esta escritora, ya que de su curiosidad indagadora y forma de abordar y representar al otro se originan muchos de sus textos ${ }^{16}$. La entrevista y sus mecanismos dan lugar a un intercambio de miradas desde diferentes ángulos de aproximación al personaje que, entrelazados armónicamente, son presentados de tal modo al lector que nos permite afirmar que el arte de la entrevista, cuando es cultivado por Elena Poniatowska, se eleva a la categoría de género literario, a un "género mayor», recordando las palabras de Sergio Pitol.

\section{BIBLIOGRAFÍA}

Leonor Arfuch, La entrevista, una invención dialógica, Barcelona, Paidós Ibérica, 1995.

- La interioridad pública: la entrevista como género, Buenos Aires, Universidad de Buenos Aires, 1992. 
M.M. Bajtín, Estética de la creación verbal, México, Siglo XXI, 1990.

Roland Barthes, El grano de la voz: entrevistas 1962-1980, México, Siglo XXI, 1983.

Sebastiá Bernal, y Albert Chillón, Periodismo informativo de creación, Barcelona, Mitre, 1985.

Rosario Castellanos, «La entrevista: un arte difícil». El mar y sus pescaditos, México, Secretaría de Educación Pública, 1975.

Albert Chillón, Literatura y periodismo. Una tradición de relaciones promiscuas, Barcelona, Aldea Global, 1999.

El País. Libro de estilo de El País, Madrid, El País, 2003.

Begoña Echeverría Llombart, Las W's del reportaje, Valencia, Fundación Universitaria San Pablo CEU, 1998.

Jorge Halperín, La entrevista periodística: intimidades de la conversación pública, Buenos Aires, Paidós, 1995.

Philippe Lejeune, Le pacte autobiographique, Paris, Éditions du Seuil, 1975.

Antonio López Hidalgo, Géneros periodísticos complementarios. Una aproximación crítica a los formatos de periodismo visual, Sevilla, Comunicación Social, 2002.

Elena Poniatowska, Domingo 7, México, Océano, 1982.

- Hasta no verte Jesús mío, México, Era, 1969.
- Las siete cabritas, México, Era, 2000.

- Palabras cruzadas, México, Era, 1961.

- Tinísima, México, Era, 1992.

- Todo México, vol. 1, México, Diana, 1990.

- Todo México, vol. 2, México, Diana, 1993.

- Todo México: la mirada que limpia [Gabriel Figueroa], vol. 3, México, Diana, 1996.

- Todo México, vol. 4, México, Diana, 1998.

- Todo México, vol. 5, México, Diana, 1999.

- Todo México, vol. 6, México, Diana, 2000.

- Todo México, vol. 7, México, Diana, 2002.

- Todo México, vol. 8, México, Diana, 2003.

Monserrat Quesada, La entrevista: el arte y la ciencia, Madrid, Eudema, 1994.

- La entrevista: obra creativa, Barcelona, Mitre, 1984.

Miriam Rodríguez Betancourt, La entrevista periodística y su dimensión literaria, Tenerife, Tauro, 2001.

Ricardo Senabre, «Sobre el estatuto genérico de la biografía», en Biografías literarias (1975-1997).

Actas del VII Seminario Internacional del Instituto de Semiótica Literaria, Teatral y Nuevas Tecnologías de la UNED, Madrid, Visor, 1998.

David Vidal, Armand Balsebre y Manuel Mateu, La entrevista en radio, televisión y prensa, Madrid, Cátedra, 1998.

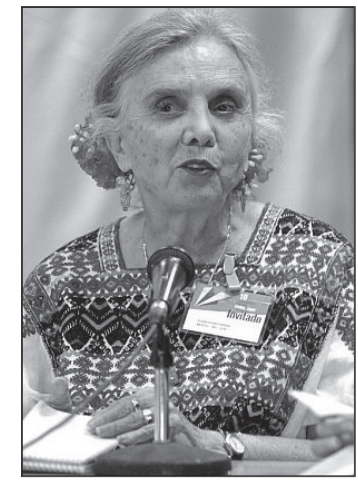

De la mirada al texto: la entrevista literaria de Elena Poniatowska 